\title{
Syntactical Structure of English and Pashto Prepositions: A Case of IN-ON Vs PUH-KE and PUH-BANDE
}

\author{
* Kainat, Undergraduate Student \\ ** Dr. Khan Sardaraz, Director ORIC
}

\begin{abstract}
Previous literature mainly focused on the categorization of prepositions in investigation of the syntactical structure of Pashto grammar. This paper will adopt syntactical model of Svenonius to examine the syntactic structure of Pashto prepositional system and will compare it with English to find out differences between English and Pashto prepositions. Svenonius' model has been applied to the structured data on preposition IN and ON in English and PUH-KE and PUH-BANDE in Pashto retrieved from different sources. Purposeful structured sample was used for analysis. The analysis revealed that the prepositional systems in two languages exhibit syntactic and semantic differences, which often affect the translation and learning of second language. The analysis also revealed that the Svenonius' model has to be adjusted to harness the syntactical structure of Pashto language. Moreover, Pashto speakers use the contact schema more often in expression of spatial relations than the English, and this paper suggests further research into spatial schemas to comprehensively analyze the Pashto prepositions.
\end{abstract}

Key words: Prepositional system, Svenonius' model, LocP, Axpart, K.

\section{Introduction}

Prepositions express relations between two entities, which may be spatial, temporal, instrumental or causal (Quirk et al., 1985). Spatial prepositions represent spatial relationships between two objects in a space or between an object and space. While, the number of spatial prepositions is small, the variety of spatial relationships denoted by them is diverse. This is the main reason of the inherent ambiguity and vagueness in the use and understanding of spatial prepositions (Chung, 2014). Prepositions have several functions, and their meanings change with change in their respective contexts. In other words, prepositions are polysemous in nature. However, in spite of the importance of prepositions in syntax and semantics, they have been discarded as "an annoying little surface peculiarity" (Jackendoff, 1973). Prepositions are of vital importance in meaning construction. They may be used to show different kinds of relationships, such as spatial relationships, temporal relationship, causes and purposes relationships, accompaniment relationships, support and or oppositions relationships (Quirk et al., 1985). This substantiates the importance of prepositions in language.

Prepositions in English have extensively been discussed in literature from different perspectives. In literature, various syntactic models have been proposed and used to investigate prepositions in English. Pantcheva (2011) investigated the direction preposition following the path schema, and proposed that the direction preposition not only needs the decomposition of path into several semantic functional heads, but there is also a spurious syncretism, as exhibited by the data. His work improved upon the Jackendoff's classification of Paths (1983). Similarly, Svenonius (2004, 2010) proposes a syntactic model for place prepositions, and decomposes the place prepositions into several semantic functional heads, such as LOC, Axpart and $\mathrm{K}$, in order to define the projection of various vectors to define the position of a Trajector (TR) within the space or Landmark (LM). His model has widely been applied to the study of prepositions in literature, as is the case with Persian (Pantcheva, 2006; Pantcheva, 2008), Hungarian (Hegedüs, 2006) and Arabic (Saeed, 2014). This model has been quite instrumental in defining the relationships between objects and the landmark, and

* Department of English and Applied Linguistics, University of Science \& Technology, Bannu

Email: kainatmatiullah@gmail.com

** University of Science \& Technology, Bannu Email: sardarazsorani@ gmail.com 
has been built on the vectors projection theory of Zwarts (1997). This paper will apply this model to the comparative study of English and Pashto prepositions.

English prepositions have also been studied from cognitive linguistic perspectives. Most of these studies locate the meaning of prepositions in human cognition and the experiential gestalts of viewing objects in the world which is structured in human conceptual system (Lakoff \& Johnson, 1999; Dodge \& Lakoff, 2005; Langacker, 2008). They argue that human sensorimotor neural structures underlie the use of preposition in language. This has also been illustrated in investigation of preposition in other languages (Sardaraz \& Ali, 2017; Sardaraz et al., 2019). Moreover, other studies have investigated the polysemous nature of English prepositions (Tyler \& Evans, 2001, 2003; Evans, 2010). This reflects that English prepositions have received in-depth investigation in previous research.

Comparative studies have been conducted between prepositions in English and other languages, which have provided significant contribution to literature. Most of the studies investigated the errors in learning English as a foreign language. Hasan and Abdullah (2009) have investigated the errors which Arabic native speakers may commit in translating English prepositions. They found that the errors in translation of one language to another is due to the difference in number of prepositions, their usage, patterns and semantics, and the different syntactic structure of the two languages. Mahmoodzadeh (2012) found that Iranian EFL learners' errors mostly constituted the wrong use of English preposition in translation of Persian to English. Saher and Saleem (2019) claim that Pakistani EFL female learners make more errors in use of English prepositions of location and direction than male. Similarly, Hanif et al. (2013) argue that native Urdu speakers commit mistakes in English prepositions because of the postpositions in Urdu language. Urdu syntactical structure i.e. Subject + Object + Verb is different from English, that Subject + Verb + Object. Pashto belongs to the IndoIranian group of languages, and this paper will investigate comparison between English and Pashto prepositions.

Pashto prepositions have received minimal treatment in Pashto grammar books. Pashto prepositions have mainly been studied from syntactical perspective, and have been classified according to the traditional linguistic methodologies. The prepositions have either been classified as pre-positions, post-position, and pre-post positions or ambipositions. The ambipositions consists of pre-position and post position which occurs together, the former comes before the object, while the later comes after the object in a lexical phrase (Tegey \& Robson, 1996). Moreover, they have either been classified as preposition of location or direction, time and mean (David, 2013). However, Pashto prepositions have not been studied from modern linguistic theories, which will throw more light on Pashto prepositions. This paper will not only test the Svenonius' model of prepositions, but also introduce new trends into Pashto language which will help in second language acquisition.

\section{Methodology}

This paper used qualitative research method to compare and contrast the use of prepositions in English and Pashto. Moreover, the syntactic structure of prepositional system was examined in the two languages. Data was collected from different sources, such as dictionaries (Zeeya, 2009) or other sources or the researchers translated either Pashto into English or English into Pashto. Structured sample was used for analysis, adopting for equal number of data-set from both languages.

Svenonius' syntactical model $(2004,2010)$ was applied for data analysis. This model follows the Zwarts' vectors projections model (1997) from space to the objects in space, and it has three heads of functional semantics, Loc, Axpart and K. Loc is also known as place, which gives stative locational meaning, denoting specific vector projection from Landmark to Trajector (TR). Loc component gives information about the physical configuration of the TR in the Landmark. Axpart means a part of the axis to which vectors are projected from the DP. In other words, Axpart identifies a region away from the DP, but forms part-whole relation with the DP. The semantic head K refers to the possession of a region by the space. Its semantic function is to point to the region(s) away from the DP as part or possession of DP, such as top, front, back, edge, bottom of DP. For example, in the interpretation of 'Child in the Rome', he proposes a bunch of vectors that project from the Rome and point toward child (Svenonius, 2010). 


\section{Data Analysis}

Pashto and English prepositions 'in' 'on' and 'puh-ke' and 'puh-bande' are analyzed below.

Preposition IN and "Puh-Ke"

The preposition 'in' in English is used for containment or enclosure of an object within a space which may be full or partial. In Pashto, the containment or enclosure sense is conveyed through the ambiposition 'بهّ - كبني 'puh-ke' construction. 'Puh' is a pre-position, while 'ke' is a post position. Analysis of the following examples will throw light on the syntactic and semantic similarities of prepositional systems of the two languages.

1.

(a) The child is in Rome

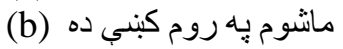

Mashum puh Rome ke de

The syntactic structure of the sentence at (1) in English and Pashto can be represented diagrammatically as below.

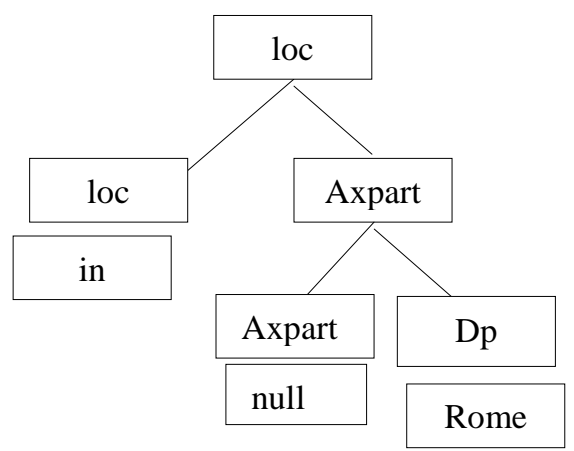

Figure 1 Syntactic structure of "In" in 1 (a)

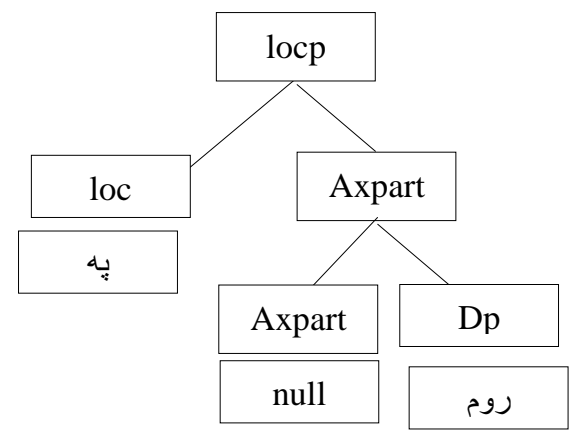

Figure 2 Syntactic Structure of "puh-ke" in 1(b)

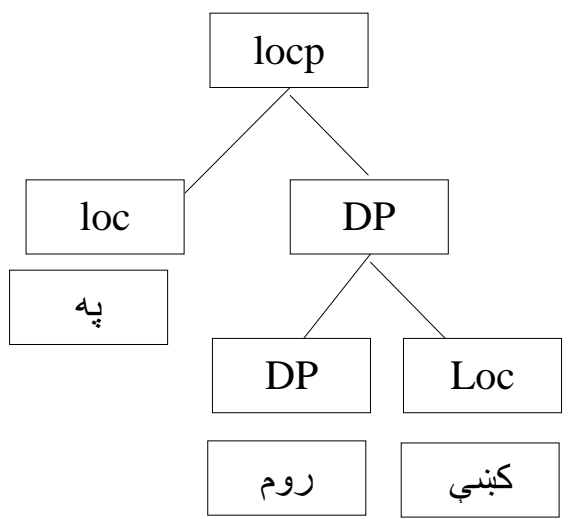

Figure 3 Syntactic structure of Pashto "pu-ke"

Figure 1 shows the diagrammatical view of preposition 'in' in 1(a) in syntactic model of Svenonius (2010). It reveals English syntactical structure as Figure-Loc-DP. Figure 2 reveals that the Svenonius' model cannot be applied to Pashto syntax in its present form, because the syntactical structure of Pashto differs from the English. Therefore, the model has to be modified to harness the semantic and syntactic features of Pashto language. Figure 3 reveals the syntactic structure of Pashto sentence at 1(b). Syntactically, the English preposition structure at sentence (1a) in Figure 1 can be represented as

$$
\begin{array}{llr}
\text { TR } & \text { LocP } & \text { DT\&DP } \\
\text { Child-NSg } & \text { in-P } & \text { the Rome NSg }
\end{array}
$$

1 (b), as shown in Figure 3 can be written as
TR
Pre-LocP
DP
PostLocP
Mashum-NSg Puh-PreP Rome-NSg ke-postP 
In English, the TR child is represented in nominative form and has spatial relation with the DP (the Rome). The syntactic structure of English and Pashto sentences at 1 (a) and (b) shows clear structural differences because of the ambiposition "puh-ke" in Pashto language. The ambiposition consists of preposition and postposition, while in English there is only preposition. Hence, the translator in translation of source language should focus on the differences between the syntactical structures of the two languages. In both the examples, the child is geographically located in an unbounded space with no specific location in Rome.

2.

(a) The child walks in front of the house.

(b) مانشوم د كور بِّه مخ كبني كرخيدو

Mashum da kor puh much ke gurzedo

In 2 (a), the child is shown in motion, while the location or landmark is exactly shown to be in front side of the house (Location). The diagrammatical representation of the sentence at 2 (a) and (b) can be represented as in Figure 4, 5 and 6.

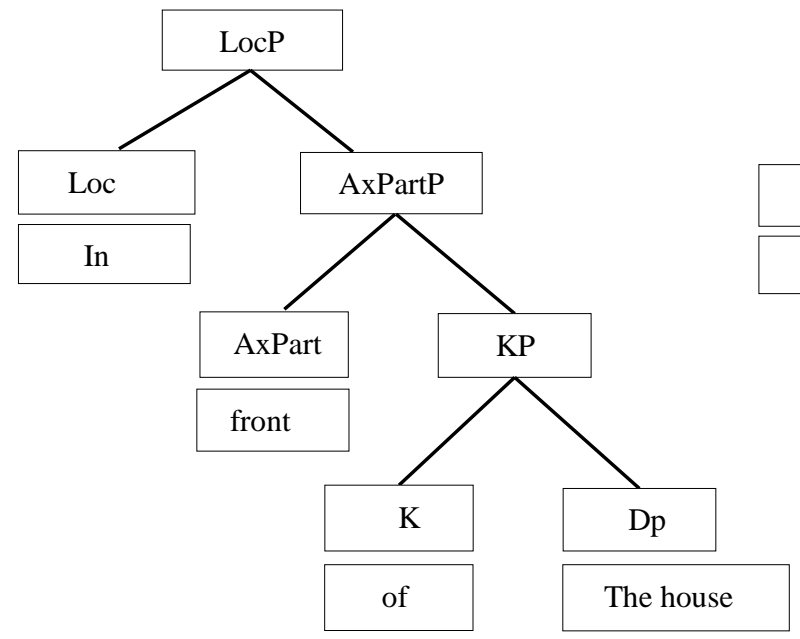

Figure 4 Syntactic structure of in front of

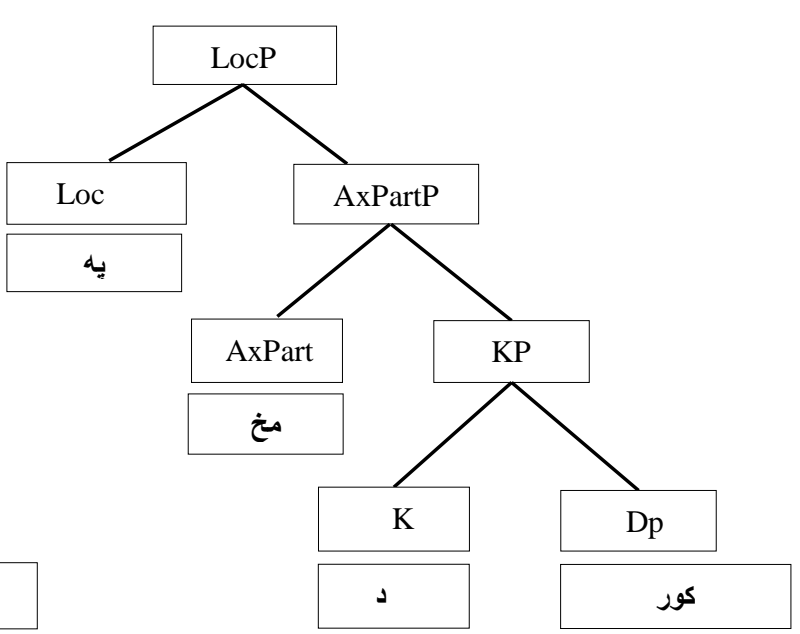

Figure 5 Syntactic structure of Puh mukh ke

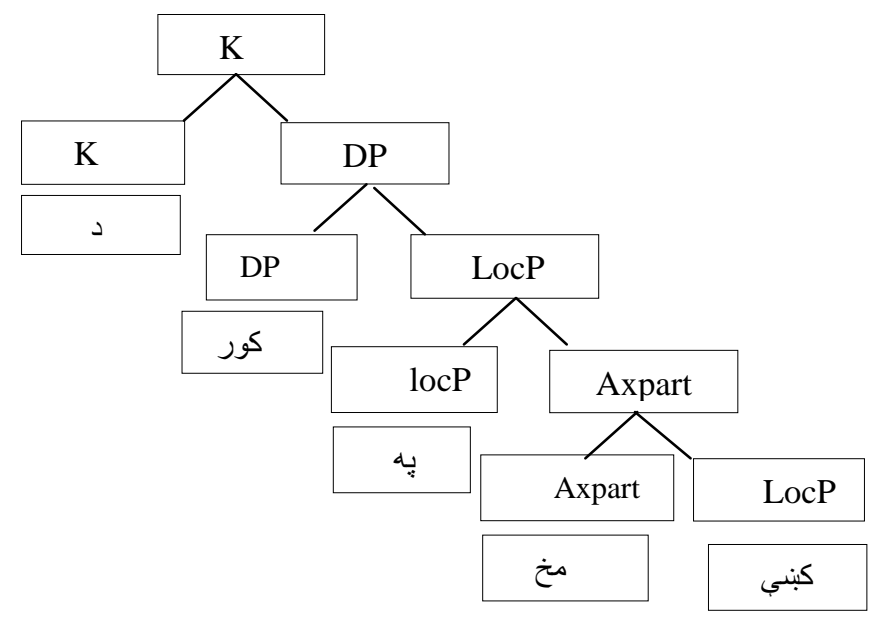

Figure 6 Syntactic Structure of "puh mukh ke"

Figure 4 shows the syntactic structure of prepositional phrase "in front of". The Figure reveals that the TR child is located in geometric boundaries of the front of the house, but keeping in view his motion, as suggested by the verb "walks", is in the form of an unspecified trajectory. In other words, only the direction of his location is known, which is in the front of the house. Figure 5 shows that the model is not adaptable to the Pashto preposition, because of the syntactical differences in the two 
languages. Figure 6 shows that in Pashto language, K (د) comes first, and is followed by DP (كور). The PreLocP and Axpart in Pashto language comes after the DP contrary to English language, and keeping in view the ambiposition in Pashto syntax, the PostLocP comes at the end. This shows that there are syntactical differences not only in the position of semantic head Loc, but also in semantic functional heads of K, Axpart and DP. Both the sentences at 2 (a) and (b) can have syntactical representation as

$\begin{array}{lcccc}\begin{array}{l}\text { TR } \\ \text { Child-NSg }\end{array} & \begin{array}{c}\text { LocP } \\ \text { in-PP }\end{array} & \begin{array}{c}\text { AxPart } \\ \text { front-Comp }\end{array} & \begin{array}{c}\text { KP } \\ \text { of-PP }\end{array} & \begin{array}{l}\text { DT\&DP } \\ \text { the house-NounSG }\end{array} \\ \text { TR } & \text { KP } & \text { DP } & \text { Pre-LocAxPart } & \text { PostLocP } \\ \text { Mashum-NSg da-PP } & \text { Kor-NSg } & \text { Puh-PreP mukh-ComP } & \text { Ke-postP }\end{array}$

In English, the TR child is represented in nominative form and has spatial relation with the DP (the house). The child is not in static position because he is bounded to walk in front of the house. He has spatial relation with front door of the house and the ground. Pashto has subject-object-verb (SOV) word order as opposed to English subject-verb-object (SVO) word order. The syntactic structure of English and Pashto at (2) shows clear structural difference because of ambiposiion in Pashto language.

3.

(a) The child is walking in the forest.

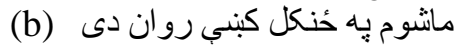

Mashum puh Tzangul ke rawaan de

In 3 (a) and (b), the child is a trajector in motion. The forest is an unspecified location. Whereas in 2 (a) and (b), Rome was a specified location with some definite geographical structure, the landmark in 3 (a) and (b), does not have definite geographical structure. The motion of the TR (child) in (2) is restricted to the area or pathway in the front of the house, but in (3), the movement of TR is not specified and restricted to some definite functional space within the Landmark. Syntactically, 3 (a) and (b) differs in semantic functional heads. Syntactic structure of 3 (a) and (b) is shown below:

$\begin{array}{lclll}\begin{array}{l}\text { TR } \\ \text { Child NSg }\end{array} & \begin{array}{c}\text { AuV } \\ \text { is }\end{array} & \begin{array}{l}\text { Verb } \\ \text { walking }\end{array} & \begin{array}{l}\text { LocP } \\ \text { in PP }\end{array} & \begin{array}{l}\text { DT\&DP } \\ \text { the forest-NSg }\end{array} \\ \begin{array}{l}\text { TR } \\ \text { Mashum-NSg }\end{array} & & \begin{array}{c}\text { Pre-Loc } \\ \text { puh-PP }\end{array} & \text { DP } & \text { Pangul-NSg } \\ \text { ZastLoc V-AuV } & \text { ke-PreP rawaan de }\end{array}$

The syntactical difference between English and Pashto shows that locative noun DP in English comes after the locative preposition 'in', while in Pashto, the locative preposition takes the form of ambiposition, a pre-locative preposition and post-locative preposition, while the Landmark DP comes in between them.

4.

(a) 'The earth is in the universe.

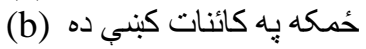

Zmukah puh kainaat ke dah

Sentences at (4) locate the earth within the unbounded Landmark (the universe). Syntactically both English and Pashto sentence exhibits different structures. English preposition syntactic structure at 4 (a) can be represented as
Figure
LocP
in-PP
DT\&DP
Earth-NSg
the Universe NSg

The syntactic structure of Pashto sentence at 4 (b), as shown in Figure can be written as

$\begin{array}{lccl}\text { Figure } & \text { Pre-LocP } & \text { DP } & \text { PostLocP } \\ \text { Zmuka-NSg } & \text { Puh-PreP } & \text { Kainat-NSg } & k e \text {-postP }\end{array}$


5.

(a) He is in school

(b) هغه يه مدرسه كبني سبق و ائي Haghah pu madrasah ke sabaq wayee

(c) $\mathrm{He}$ is in the school

هغه يه مدرسه كبني دي (d) Haghah puh madrasah ke de

(e) $\mathrm{He}$ is in hospital

هغه به اسيتّال كبني داخل دي (f) Haghah pu aspathaal ke dakhel de

(g) He is in the Hospital

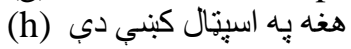

Haghah pu aspathaal ke de

In (5), English and Pashto show semantic variations in English, if the article 'the' is placed before the DP. Semantically, sentences in 5 (a) and (c) and (e) and (g) are different, because of the article 'the', denoting admission in school and hospital in (a) and (c), while physical presence in (d) and (g). However, Pashto does not exhibit such variations, as is evident from 5 (b), (d) (f) and (h), where semantic variations need change in syntax by adding both noun and verb as in (b) or only verb as in (f). Absence of articles in Pashto language leads Pashto speakers to commit mistakes in the use of articles in English. Syntactical differences between English and Pashto also exist and they follow the same patterns as illustrated in preceding examples.

The prepositions may show semantic differences in both the languages depending upon the lexical construction. Consider the following.

6.

(a) There are flower in the vase

(b) به كلدانى كبني كلان دي Puh guldanai ke gulaan di

(c) There is a crack in the vase

(d) به كلدانى كنبي جاود دي

Puh guldani ke chawd de

In 5 (a) and (b), there is containment sense of partial enclosure. The flower is represented as partially enclosed with the stems of the flower inside while the flowery part outside the vase. Hence, the preposition 'in' and 'puh-ke' reflect partial enclosure sense, which can be diagrammatically represented in Figure 7.

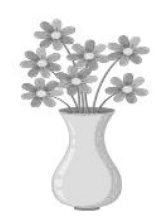

Figure 7 Visual representation of (a) and (b)

Figure 7 clearly shows that the stems of the flowers are inside the vase, but the flowers are outside the vase. So, it reflects partial enclosure sense. The lines at 5 (c) and (d) shows a crack in the frame of the vase, which is related to the structure of the vase, as there is vacuum in landmark itself. The crack serves as TR in the structure of vase (LM), which is not an enclosure sense, rather, it configures the crack within the frame of the landmark boundary, as shown in Figure 8.

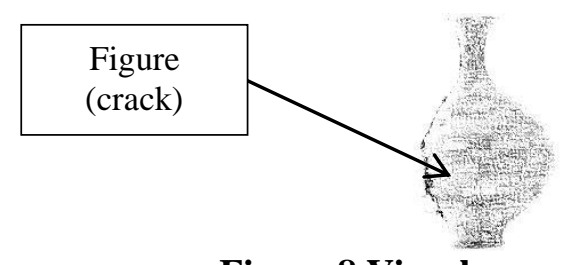

Figure 8 Visual representation of (c) and (d) 
This shows that simple approach to the semantics of preposition as denoting spatial geometric relations between two objects may not be accommodative in all cases. This refers to the semantic diversity of the prepositions, which depends upon the linguistic context. However, both English and Pashto shows similarity in the above cases, they differ in syntactic properties, as DP comes first in Pashto while the TR comes first in English, and the DP follows the preposition in English, while it is preceded by pre-position and followed by post-position.

Preposition 'in' has also been used in temporal relationship across languages. Both English and Pashto use the same preposition for reflecting time as container. Consider the following.

7.

(a) I will do it in one day

زه به دا به يوه ورخ كبنسي كوم (bah

Zuh bah da puh ywah wratz ke kawum

(c) He has to complete it in one year

هغه به دا بِه يوكال كبني يوره كوي (d)

Haghah bah daa puh yo kaal ke purah kawi

In these sentences, the preposition relates an act as a physical object within specific time. Time is represented as Landmark, and has spatial configuration with reference to the act. Both English and Pashto exhibits the semantic diversity of prepositions, though they may differ in use of different preposition for the same sense or same preposition for different senses, as is the case with the following example,

8.

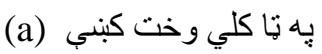
Puh taakuli wakhth ke

(b) at the appointed time

In the phrases at 8 (a), ambiposition "puh-ke" has been used, which are spatial ambiposition for locating objects in space. But, in 8 (b), the preposition ' $a t$ ' has been used for the fixed time, which is represented as a landmark in space. In all these cases, the syntactic patterns of English and Pashto differ from one another, and can be represented respectively as

$$
\begin{array}{ccr}
\text { TR } & \text { LocP } & \text { DP (Time) } \\
\text { PreLocP } & \text { DP (Time) } & \text { PostLocP }
\end{array}
$$

These prepositions are also used with abstract nouns and concepts, where they get metaphoric nature, as is the case with the following.

9.

(a) هغه بِه مصيبت كنبي دي

Haghah puh musibat ke de

10.

(b) $\mathrm{He}$ is in trouble

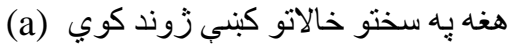

Haghah puh sakhto halaatho ke zhund kawi

(b) He is passing life in stringent conditions

Both in 9 and 10, the abstract concepts of "musibat" and "halaato" in Pashto and "trouble" and "conditions" have been used as Landmark to which the TR "haghah" and "he" are related in spatial terms through the ambiposition "puh-ke" in Pashto and "in" in English. The use of the ambiposition in Pashto and preposition in English in these examples is metaphoric, because there is no specific TR and LM relation in these linguistic contexts. These examples show that the prepositions do not have fixed semantic value, but are dependent upon the context for its meanings. Syntactically, both English and Pashto exhibit the same difference, already pointed out in preceding examples. 


\section{Preposition ON and 'Puh-Bande'}

The preposition 'on' in English defines the support and contact between the TR and the LM. The

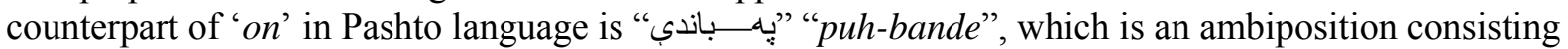
of pre-post position structure. The pre-post positions are two elements which precede and follow a noun or object or part of an object or place. Keeping in view the structural difference of these two prepositions in two languages, some of the examples of both are analyzed below.

11.

(a) The cup is on the table.

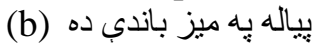

Piyalah puh mez bande de

Syntactical structure of both the sentences at 11 (a) and (b) are the same, reflecting the TR + $\mathrm{AV}+$ Noun and TR + Noun + AV respectively. However, ambiposition in Pashto differentiate the overall syntactic structure of the sentences. Applying the Svenenious' model, diagrammatically, the sentences can be represented in Figure 9, 10 and 11.

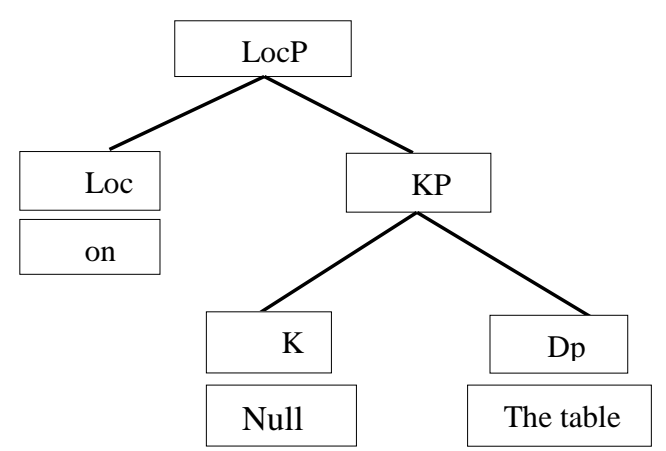

Figure 9 Syntactic representation of (a)

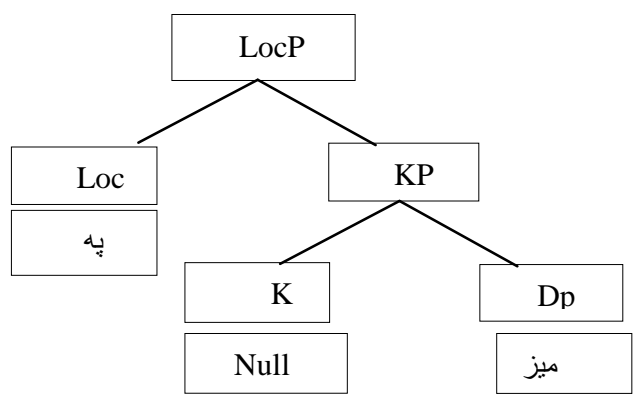

Figure 10 Syntactic representation of (b)

Figure 9 and 10 reveal that the Svenonius' model cannot be applied to Pashto language in its present form, rather it has to be modified as PreLocp + DP + PostLocp, as represented in the Figure 11.

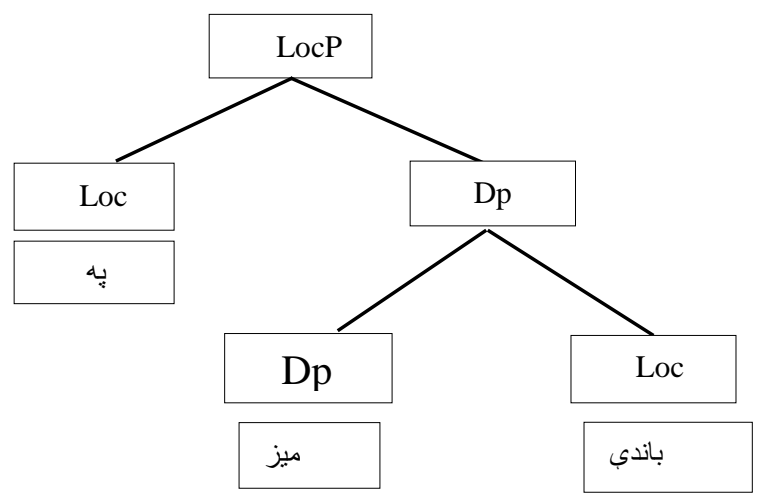

Figure 11 Syntactic representation of (b)

Figure 11 shows the diagrammatical view of ambiposition "puh-bande", which reveals that Svenonius' model has to be modified to harness the syntactic structure of Pashto prepositions. Syntactically, the English preposition structure at sentence 11 (a) and (b) in Figure 9 and 11 written as;

$\begin{array}{lccc}\begin{array}{l}\text { TR } \\ \text { Cup-NSg }\end{array} & \begin{array}{c}\text { LocP } \\ \text { on-P }\end{array} & \begin{array}{c}\text { DT\&DP } \\ \text { the table-NSg }\end{array} \\ \begin{array}{l}\text { TR } \\ \text { Piyala-NSg }\end{array} & \begin{array}{c}\text { Pre-LocP } \\ \text { Puh-PreP }\end{array} & \begin{array}{c}\text { DP } \\ \text { mez-NSg }\end{array} & \begin{array}{c}\text { PostLocP } \\ \text { bande-PostP }\end{array}\end{array}$


No doubt, both sentences differ in their syntactic structure, but semantically, they represent the contact between the TR (Cup) and the landmark (table). The cup is in contact with upper side of the table. The spatial scene involves support function between the table and the cup.

12.

(a) The book is lying on the edge of the table

(b) كتاب دمبز بر ختنده دئ

Kithab da mez par Tsundah da

Example 12 (a) shows the prepositional phrase "on the edge of", which include the functional heads Loc, Axpart and K. The preposition "on- puh--bande" reflects the functional head Loc. It shows relationship of the object with Landmark. In other words, spatial relation of the book with the table is shown. Axpart (edge-Tsundah) refers to the functional space within the landmark (table), where the object is located. The semantic functional head $\mathrm{K}(o f-d a)$ refers to the possession by Landmark of its edge. This shows that the semantic functional heads in Pashto and English are the same. However, the analysis reveals syntactical difference. The syntactic structure of the sentence at 2 (a) is represented diagrammatically in Figure 12. 13 and 14.

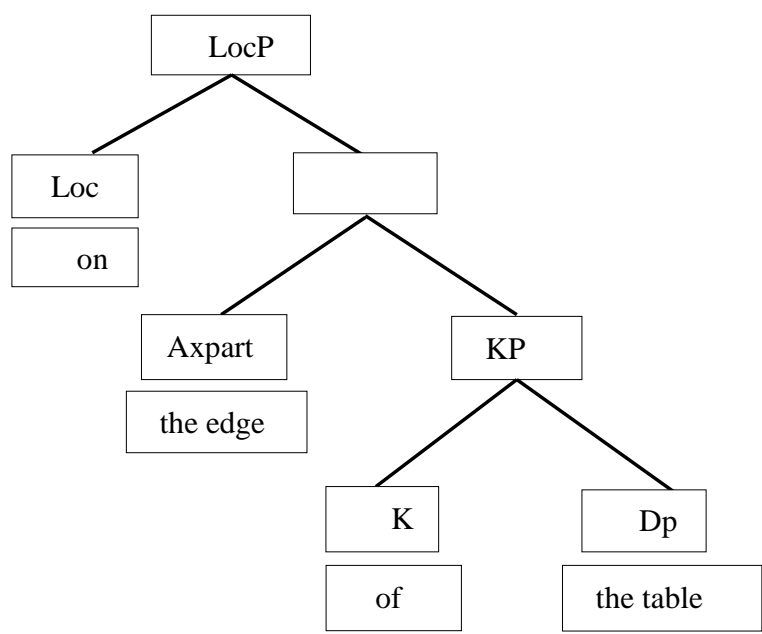

Figure 12 Syntactical representation of "on the edge of"

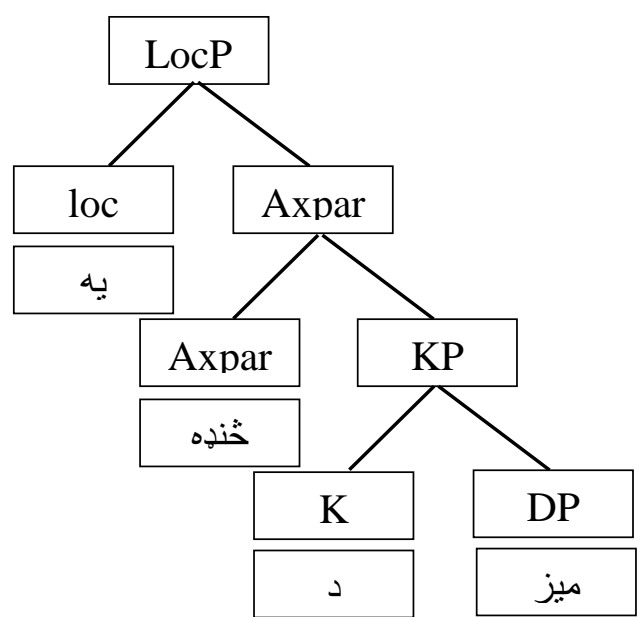

Figure 13 Syntactical representation of "da mez puh Tsundah"

Figure 12 shows that English follows the Svenonius' model, but in Pashto, it cannot accommodate the variations in the syntactic structure of compound prepositions and sentence structure. Therefore, as in Figure 11, it has to be modified as in Figure 14.

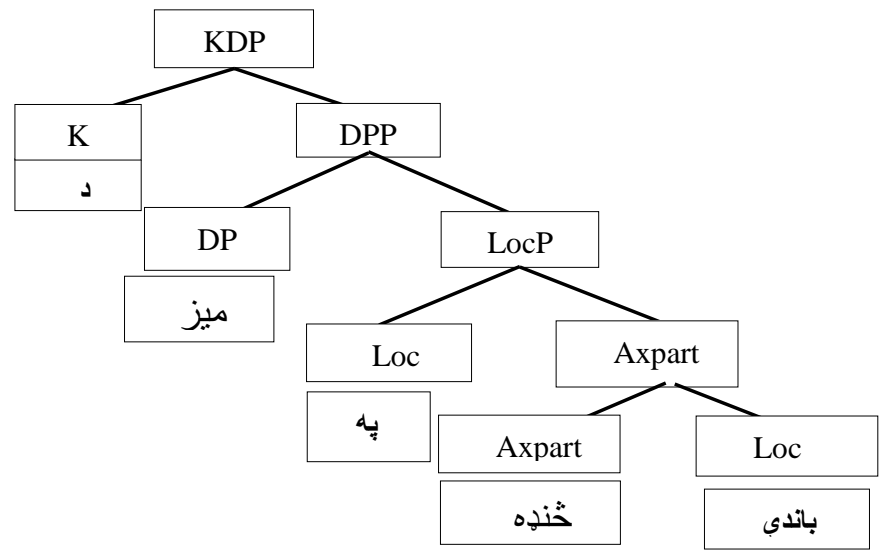

Figure 14 Syntactic representation of "da mez puh Tsundah"

Figure 14 reveals that in a noun phrase with compound preposition, the functional head $\mathrm{K}$ comes at the beginning, which reflects the possession of noun DP of its regions Axpart, relating the TR to LM trough the ambiposition PreLocP and PostLocP. This shows that in compound prepositions, 
besides the difference of preposition 'in' in English and ambiposition in Pashto, the possessive preposition is also differently used in the two languages.

The syntactic structure at 12 (a) and (b) is written as



كتاب را نه بِه مبز بِاني شو (a)

Kithaab raanah puh mez pathe sho

(b) I left the book on the table (Zeeya 2009)

In 13, the syntactic structure of prepositions in Pashto language corresponds to the English prepositions. The noun phrase 'on the table' in English is similar to 'puh mez-on table' in Pashto language. However, the syntactical structure of Pashto in 13 (a) is different from English at 13 (b), as the verb 'pathe sho' comes at the end in Pashto, while it is in the beginning in English. In 'puh-bande' ambipositions, the second element is often dropped in Pashto language, contrary to 'pu-ke" where the first element is often dropped.

14.

(a) الوتكه بِر بناركرزبِ (a)

Alwathukah par haar gurzedah

(b) the aircraft circled over the city (Zeeya 2009)

The Pashto preposition 'puh' used in the 14 (a) has been used in the sense of over. It means that in Pashto, as in English, a preposition can be used for an extended meaning, as the aircraft has no contact with or support with the landmark, rather it has vertical relation with the city. In English, the preposition 'over' is used to denote such a relationship. Hence, the languages may use different prepositions for the same sense. Similar is the case with the following.

15.

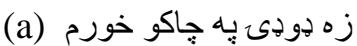

Zuh dodai puh chaku khrum

(b) I eat with a knife (David 2013)

16.

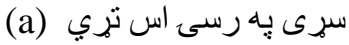

Sarhi puh rasai Aas tharhi

(b) "The man ties the horse up with a rope" (David 2013)

In 15-16 (a), the preposition 'puh' has been used, which as earlier stated, is equivalent to English preposition 'on'. However, 'puh' in 15 (a) carries the sense of means or instrument, which is used an instrument or mean. 15-16 (b) shows that English employs the preposition 'with' for means or instrument. Hence, 15-16 (a) and (b) shows that Pashto and English may use different prepositions for the same sense. In 15 and 16, the relationship is one of means rather than of static spatial co-relations. The preposition 'puh' precedes the noun 'chaku', but 'chaku' has vertical co-relation with 'dodaibread', and 'puh' does not represent bread on the knife, rather the knife-chaku is on the bread. Hence, the TRs in 15 and 16 are 'zuh-I' and 'sarhe-the man', 'dodai-bread' and 'Aas-horse' are LMs, while 'chaku-knife' and rasai-rope are means which have causal spatial co-relationship with the TRs and LMs.

17.

(a) احمد بِه هغه شِّه دبِر نبششه وو

Ahmad puh haghah shpah der nishah wu

(b) 'Ahmad was very drunk on that night.' (David 2013)

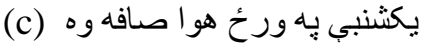

Yakshambe puh wratz hawaa safah wah

(d) The weather was clear on Sunday. (Zeeya 2009)

18.

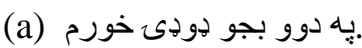

(b) I eat at two o'clock (David 2013) 
The examples at 17, 18 and 19 show the temporal use of prepositions. Spatial prepositions 'puh' and 'on' are used to represent temporal relationships. In 17 (a) and (b), the TR Ahmad is shown as in contact with time like a physical functional space, while in (c) and (d), the temporal nouns "wratz-day" and 'on Sunday' are represented as physical functional space, where something is happening. However, in Pashto, common temporal noun must follow a proper temporal noun, and in the absence of common noun, the temporal proper noun will take any other preposition like

19.

(a) هغه به جمعي ته رائي

Haghah bah jume ta ratzi

(b) He will come on Friday.

In 19 (a), the preposition 'thah' is from the source-goal-path schema, while the preposition 'puh' is from contact and support schema. Hence, the change of single lexical item may cause the change of preposition in Pashto language, while in English, the same preposition is used. In 18 (a) and (b), temporal relationship are represented in spatial terms, but in English 18 (b), another preposition ' $a t$ ' is used, which encodes the meaning of close proximity or practical association (Evans 2010). However, in 18 (b), ' $p u h$ ' is used for such kind of relationships. This shows that English prepositional system is more extensive than Pashto, as the same preposition is used for different kinds of senses in Pashto language.

20.

زما پِه خبري فكر وكرئ (a)

Zumah puh khabure fikr wurkrhai

(b) Think over my words

(c) بهو اقعاتو باندي رنيا اجول

Puh waqa'atho bande ranrha achawul

(d) to throw some light on the situation

(e) ير يو شي باندي اصرار كول

Par yo shi bande israar kawul

(f) To insist upon something

زه بر تا باندي اعتقاد نه لرم (g)

Zuh par taa ia 'theqaad nuh larum

(h) I do not have trust upon you (Zeeya 2009)

In 20, the preposition 'on' and 'puh-bande' have metaphorically been used. In 20 (a) and (b), the lexical items 'khabure' and 'words' are not physical objects, but are abstract concepts which get spatial representation through the use of spatial prepositions. In (c) and (d), both the situations are spatially represented, while the light is metaphorically denoting explanation of the situation. In (e) and (g), 'yo shi-something', and 'ia'theqad-trust' are metaphorically used, as they are not physical objects. but are represented as physical object through the spatial prepositions. Thus, both English and Pashto reveal metaphorical use of prepositions, but syntactically both languages differ in the use of prepositions, which can be represented as below.

English syntactical structure

\section{LocP DT+DP}

Pashto syntactical structure

\section{Discussions}

$$
\text { Pre-LocP +DP +Post-LocP }
$$

The analysis reveals that the English prepositions 'in' and 'on' and Pashto ambipositions 'puh-ke' and 'puh-bande' have significant syntactic differences. English language mainly uses prepositions, while Pashto language uses prepositions, pre-post positions and circum-positions. The syntactical differences are mainly due to the ambipositions in Pashto language. In simple prepositions, the syntactical structures of the two languages differ because of preLocP or pre-position and postLocP or post position in Pashto language. The TR and LM have the same syntactic structure, TR being followed by the LM. However, sometimes, LM in Pashto comes before the TR, as is the case in (6). In compound prepositions, the syntactical structure differ more in the two languages as is evident at 3 (a) and (b) and 12 (a) and (b), where the Axpart comes after DP, and K comes in the beginning, while PreLocP and PostLocP comes before and after Axpart respectively. Hence, compound prepositions 
may cause problems for the second language learners, and knowledge of syntactical differences will help in solving these issues. Thus, this paper will be instrumental in creating interest in comparative linguistic across cultures to find out the differences in the prepositional systems of different languages.

This paper extends further the classification of prepositions in Pashto language. Traditional linguistic approaches (Tegey \& Robson, 1996; David, 2013) mainly concerned themselves with syntactical categorization of prepositions in Pashto language as preposition, post position, ambiposition and circumposition. But, this paper decomposes the spatial locative prepositions into functional semantic heads, which are PreLocP, PostLocP, Axpart, and K. In other words, the spatial relations objects in a location has been This decomposition of locative prepositions will pave the way for further research into Pashto prepositional system, which will bring new insights into the Pashto prepositional system.

The analysis also reveals that Svenonius' model cannot be applied to Pashto language in its present form rather it has to be modified to be applied to Pashto language. LocP has to be modified as PreLocP and PostLocP besides other structural modifications as evident in (3), (6) and (12), represented in Figures 3 and Figure 14. Hence, though the basics of this model are applicable to Pashto prepositional system, yet some modifications are required to adopt it for Pashto language. This model may prove helpful in further exploration of Pashto prepositional system, which will contribute not only to the grammar of Pashto language but will also be helpful in applied linguistics.

The analysis also reveals important semantic differences between Pashto and English prepositions. The use of article 'the' before the locative noun changes the meaning of the sentence, as is seen in (5). However, the absence of articles in Pashto makes it difficult for the English learners to determine the difference in such sentences. Moreover, the same sense may be conveyed by different prepositions in the two languages, as found in (14) to (19). Sometimes, the preposition may require a specific noun, which if not present in the sentence, will take another preposition as seen in (18) and (19). These findings will contribute to the Pashto language and applied linguistics, and will help the second language learners to know the differences in the prepositional system between the two languages.

One of the most important findings of this paper is that the Pashto speakers use more frequently the contact and support schema in expression of spatial relationships than the English speakers. The Pashto preposition ' $p u h$ ' is equivalent to English preposition 'on', which is used both in those sentences conveying the enclosure or containment sense. Pashto speakers express not only the containment sense of spatial relationships, but also the contact relationship of the object with the upper surface of the space containing the object. This paper recommends further research into exploring different spatial schemas, which underlie the use of spatial prepositions.

\section{Conclusion}

The findings reveal syntactic and semantic similarities and differences in the prepositional systems of Pashto and English. These differences in the prepositional systems of the two languages cause the second language learners to make mistakes in translation and comprehension of language. The Svenonius' model of spatial Ps in Pashto show that the model, based on projection of vectors from landmark to the object, gives a new dimension to the study of Pashto prepositional system. However, the model has to be revisited to adopt it to the Pashto prepositional system. The application of this model will change the traditional approach to the Pashto preposition, and will further enrich literature on Pashto prepositional system. The findings also reveal that Pashto speakers are tilted towards using contact schema more than the English speakers, and this paper recommends further research into exploring the spatial schemas underlying the use of spatial prepositions.

\section{References}

Chung, E. (2014). Verification of a Polysemous Spatial Preposition-ON. 언어정보 19: 167-188.

David, A. (2013). Descriptive grammar of Pashto and its dialects. Walter de Gruyter.

Dodge, E., \& Lakoff, G. (2005). Image schemas: From linguistic analysis to neural grounding. In B.

Hampe and J. Grady (Eds,). From perception to meaning: Image schemas in cognitive linguistics, (pp-57-91). Berlin: Mouton de Gruyter. 
Evans, V. (2010). From the spatial to the non-spatial: The 'state'lexical concepts of in, on and at. In V. Evans and P. Chilton (Eds,). Language. Cognition and space: The state of the art and new directions, (pp-171-193). London: Equinox Publishing.

Hanif, A. et al. (2013). Comparative analysis of English and Urdu grammar.

Hasan, A. A. \& Abdullah I. H. (2009). A comparative study of English and Arabic use of prepositions amongst Arab native speakers. Unpublished manuscript). Universiti Kebangsaan Malaysia.

Hegedüs, V. (2006). Hungarian spatial PPs. In P. Svenonius (eds,). Nordlyd: Troms $\emptyset$ Working Papers in Linguistics: 33.2, Special Issue on Adpositions, (pp-220-2330. Tromsø: Center for Advanced Study in Theoretical Linguistics.

Jackendoff, R. (1973). The base rules for prepositional phrases. In S. R. Anderson and P. Kiparky (eds,). A Festschrift for Morris Halle, (pp-345-356). New York: Holt Rinehart and Winston Inc.

Jackendoff, R. (1983). Semantics and cognition. Cambridge: MIT press.

Lakoff, G., \& Johnson M. (1999). Philosophy in the flesh: The embodied mind and its challenge to Western thought. New York NY, Basic books.

Langacker, R. W. (2008). Cognitive grammar: A basic introduction. OUP: USA.

Mahmoodzadeh, M. (2012). A Cross-linguistic Study of Prepositions in Persian and English: The Effect of Transfer. Theory \& Practice in Language Studies 2(4): 734-740.

Pantcheva, M. (2006). Persian preposition classes. In Svenonius and Pantcheva (eds,). Roms $\phi$ Working Papers on Language and Linguistics: Nordlyd 33, special issue on Adpositions (pp1-25). Troms $\varnothing$ : University of Troms $\emptyset$.

Pantcheva, M. (2008). The place of PLACE in Persian. In P. A. Asbury, B. Gehrke and R. Nouwen (eds,). Syntax and semantics of spatial $P$ (pp-120: 305). Amsterdam: John Benjamins Publishing.

Pantcheva, M. B. (2011). Decomposing path: The nanosyntax of directional expressions. (doctoral dissertation) Faculty of Humanities, Social Sciences and Education. Troms $\emptyset$, Universiteteti Tromsø. Ph D.

Quirk, R. et al. (1985). A comprehensive grammar of the English language. London: Longman.

Saeed, S. (2014). The syntax and semantics of Arabic spatial PS. Newcastle and North Umbria Working Papers in Linguistics 20: 44-66.

Saher, N., \& Saleem M. F. (2019). An Analysis of Prepositional Errors Committed by Undergraduate ESL Learners of Pakistan. Journal of Literature, Languages and Linguistics 53: 9-15.

Sardaraz, K. \& Ali R. (2017). A cognitive-semantic study of the spatial preposition fì (في (ف) in the Quran. KEMANUSIAAN: The Asian Journal of Humanities 24(2): 89-122.

Sardaraz, K., Badshah, S. N., \& Khan, I. U. (2019). Cognitive Semantic Study of the Preposition 'Min'in the Quran. Cognitive Semantic Study of the Preposition 'Min'in the Quran 4(2), 83109.

Svenonius, P. (2004). Spatial P in English. ms. University of Troms $\varnothing$.

Svenonius, P. (2010). Spatial p in English. In G. Cinque and L. Rizzi (eds,). Mapping spatial PPs: The cartography of syntactic structures 6 (pp-127-160). Oxford: Oxford University Press.

Tegey, H. \& Robson B. (1996). A Reference Grammar of Pashto. Washington: Center for Applied Linguistics.

Tyler, A. \& Evans V. (2001). Reconsidering prepositional polysemy networks: The case of over. Language 77(4): 724-765.

Tyler, A. \& Evans V. (2003). The semantics of English prepositions: Spatial scenes, embodied meaning, and cognition. Cambridge: Cambridge University Press.

Zeeya, A. P. (2009). Pashto-English Dictionary. Hyattsville: Dunwoody Press.

Zwarts, J. (1997). Vectors as Relative Positions: A Compositional Semantics of Modified PPs1. Journal of semantics 14(1): 57-86. 